\title{
Medievalista
}

Online

$30 \mid 2021$

Número 30

\section{AYALA MARTÍNEZ, Carlos de; FERNANDES, Isabel Cristina Ferreira; PALACIOS ONTALVA, Santiago (coords.) - La Reconquista. Ideología y justificación de la Guerra Santa Peninsular. Madrid: La Ergastula, 2019 (534 pp.)}

\section{Claudio Neto}

\section{(2) OpenEdition}

\section{Journals}

\section{Edição electrónica}

URL: https://journals.openedition.org/medievalista/4603

DOI: 10.4000/medievalista.4603

ISSN: $1646-740 X$

\section{Editora}

Instituto de Estudos Medievais - FCSH-UNL

\section{Refêrencia eletrónica}

Claudio Neto, «AYALA MARTÍNEZ, Carlos de; FERNANDES, Isabel Cristina Ferreira; PALACIOS

ONTALVA, Santiago (coords.) - La Reconquista. Ideología y justificación de la Guerra Santa Peninsular Madrid: La Ergastula, 2019 (534 pp.)», Medievalista [Online], 30 | 2021, posto online no dia 01 julho 2021, consultado o 24 julho 2021. URL: http://journals.openedition.org/medievalista/4603 ; DOI: https://doi.org/10.4000/medievalista.4603

Este documento foi criado de forma automática no dia 24 julho 2021.

Mediavalista está licenciado com uma Licença Creative Commons - Atribuição-NãoComercial 4.0 Internacional. 


\title{
AYALA MARTÍNEZ, Carlos de; FERNANDES, Isabel Cristina Ferreira; PALACIOS ONTALVA, Santiago (coords.) - La Reconquista. Ideología y justificación de la Guerra Santa Peninsular. Madrid: La Ergastula, 2019 (534 pp.)
}

\author{
Claudio Neto
}

\section{REFERÊNCIA}

AYALA MARTÍNEZ, Carlos de; FERNANDES, Isabel Cristina Ferreira; PALACIOS ONTALVA, Santiago (coords.) - La Reconquista. Ideología y justificación de la Guerra Santa Peninsular. Madrid: La Ergastula, 534 pp.

\section{NOTA DO EDITOR}

Data recepção do artigo / Received for publication: 8 de Fevereiro de 2021

Na última década, quem tenha seguido com atenção a renovação dos estudos sobre ideologia e materialidades do conflito que opôs Cristãos e Muçulmanos na Península Ibérica entre os séculos VIII e XV não se surpreenderá com a edição de um novo conjunto de textos, a finais de 2019, dedicado à edição das actas do Colóquio levado a cabo em Palmela sensivelmente um ano antes, cujos trabalhos se subordinaram ao tema que nomeia o presente volume: La Reconquista. Ideología y justificación de la Guerra Santa 
peninsular. A edição apresenta-se no esteio de um conjunto de publicações tematicamente relacionadas e resulta da vitalidade de uma iniciativa de investigação dedicada ao tema que conta já com dois projectos I+D financiados pelas autoridades espanholas ${ }^{1}$, que tem tido o mérito de reunir um vasto elenco de especialistas de diversas nacionalidades. Sucessivos encontros científicos realizados sob a égide desta iniciativa e dedicados à amplitude do tema têm constituído um importante veio de abordagem e problematização das questões em torno do confronto que opôs os poderes Cristãos peninsulares ao Al-Andalus. A pertinente e atempada publicação das actas das discussões resultantes tem propiciado à comunidade científica um renovado dossier de estudos e questões relacionados com a Guerra Santa, a Jihad e a Cruzada no palco ibérico medieval ${ }^{2}$.

2 A obra, coordenada por Carlos de Ayala Martínez, Isabel Cristina F. Fernandes e J. Santiago Palacios Ontalva, marca a etapa do percurso de reflexão e debate acima aludido em que a equipa responsável tomou como objectivo a discussão sobre o conceito de Reconquista, procurando não só retomar as considerações em torno da carga historiográfica e utilização do termo, como também projectá-lo nas suas dimensões medievais, quer ao nível das textualidades, quer ao nível da cultura material. Exige-se actualmente que os medievalistas estejam cientes da carga ideológica deste conceito. $O$ seu emprego - ou recusa em fazê-lo - tem marcado opções de abordagem teórica e metodológica nos trabalhos da recente historiografia que se debruça sobre os vários aspectos do confronto entre Cristandade e Islão peninsulares durante a Idade Média. Surgido nos finais de Setecentos e consolidado o seu uso a meados da centúria seguinte, conforme é referido a várias passagens da obra em apreciação, o termo foi finalmente alçado a chave interpretativa da nacionalidade espanhola e legitimação da sua unidade pela pena de Sánchez Albornoz. Desde os anos de 1970 do século XX³ , o conceito tem dividido historiadores e pensadores da medievalidade e dos fenómenos nacionais ibéricos quanto à sua carga simbólica e legitimidade do seu emprego. Trata-se, no fundo, da discussão em torno de um mito fundacional: Pelágio, membro da aristocracia guerreira visigoda, recusando a dominação muçulmana, refugia-se nas Astúrias. A sua revolta é consagrada pelo triunfo militar perante a superioridade numérica do invasor. Neste homem e na sua acção encarnam o que poderíamos apelidar de código genético da ideia de uma Espanha restaurada - a ligação com a monarquia de Toledo, a resistência contra o invasor, a inabalável fé Cristã perante um outro professante um credo alienígena.

3 Conforme veremos adiante através de um dos contributos deste volume, o mito não teve o mesmo eco em Portugal, embora não tenha sido frontalmente recusado de imediato. Alexandre Herculano, hoje já longe do lugar merecido nos programas de ensino oficiais, aproveitava-o no seu inesquecível Eurico, e os historiadores do século $\mathrm{XX}$ foram fazendo a releitura dos antecedentes da nacionalidade à luz de uma linhagem de conjunturas derivadas de Covadonga. Foi a renovação do medievalismo português já em regime democrático que, como em muitos outros aspectos, foi trazendo tomadas de posição relativamente ao problema. Os anos de 1992 e 1993 viam surgir duas iniciativas editoriais onde a crítica ao termo Reconquista era publicada: José Mattoso tratava brevemente a questão no primeiro volume da sua História de Portugal, defendendo que a ideia de continuidade entre a monarquia visigoda e o reino asturiano-leonês assentava em bases pouco credíveis perante a crítica moderna das evidências disponíveis; descrevia o termo Reconquista como um equívoco historiográfico ${ }^{4}$. Já Maria Ângela 
Beirante, não recusando o termo, intitulava o seu capítulo sobre os poderes Cristãos nortenhos entre os séculos VIII e XI na Nova História de Portugal de A «Reconquista» Cristã, a palavra aspada denunciando já a proximidade com o criticismo do termo, exposto na introdução ao capítulo .

Não foram suficientes, no entanto, estes e outros contributos para selar o tema e inculcar na historiografia ibérica um consenso acerca da utilização do conceito. 0 debate perdura nos dois países com ramificações que, compreendendo a Academia nas suas múltiplas manifestações, abarcam também a esfera política e os usos mais comuns da História. E se os académicos portugueses têm renovado os pontos de vista e insistido no aclaramento do conceito e da sua herança historiográfica ${ }^{6}$, não é menos verdade que o assunto Reconquista tem tido ecos na esfera pública portuguesa: como não pensar que o recente debate relativo à conservação dos achados na Sé de Lisboa não encerra em si mesmo concepções patrimoniais relacionadas com uma visão sobre as tensões e confrontos entre o poder Muçulmano e o poder Cristão na cidade? ? Ou ainda, como não prestar atenção à mais recente exposição temporária do Museu Nacional de Arte Antiga $^{8}$, cujo nome Guerreiros e Mártires. A Cristandade e o Islão na Formação de Portugal estabelece, à partida, uma dualidade de confluências na formação da nacionalidade, ao invés de um triunfalismo de Cristãos sobre Mouros ${ }^{9}$.

5 Assumindo uma legítima pertinência, o volume inicia-se com um apartado dedicado à exploração do tema nas suas origens historiográficas mais remotas e à discussão relativa ao emprego do mesmo na actualidade. C. de Ayala Martínez (pp. 17-52) apresenta uma estratigrafia textual do mito de Pelágio e sua plasmação entre os ecos dos testemunhos árabes do século VIII e a sua consagração tardo-medieval. Recuperando a possível historicidade do protagonista e a sua transformação em figura central do discurso reconquistador, C. de Ayala convida a percorrer os momentos-chave da construção do mito, desde as formulações das crónicas Rotense e Ovetense, passando por um período de algum silêncio, à recuperação e integração do mesmo no âmbito das lógicas culturais de reforço e engrandecimento da Sé de Oviedo levadas a cabo pelo Bispo Pelayo (1101-1153). Por seu turno, Alexander P. Bronisch (pp. 53-77) detém-se na análise das crónicas Rotense e Ovetense, apresentando uma leitura de ambas que busca os aspectos prováveis das mesmas, ou, pelo menos, as potencialidades de uma veracidade contida nestes textos. Talvez a maior virtude da sua análise seja compreender que as formulações do neogoticismo atribuído aos scriptoria coevos de Afonso III das Astúrias não são unívocas, estando nelas já sediadas duas posturas diferentes relativas à natureza da realeza de Pelágio, e, consequentemente, da realeza Asturiana: de acordo com o autor, o paralelo que Pelágio assume face a Wamba na sua representação no texto Rotense está muito associado a uma institucionalização da monarquia asturiana, notando-se um rompimento com o reino e a Igreja visigodas; por outro lado, o texto Ovetense pretende insistir na continuidade Toledo-Astúrias, modificando o texto Rotense e construindo um argumento genealógico na pessoa de Pelágio de forma a personificar esta continuidade.

6 A segunda metade da primeira parte da obra é composta por dois artigos cujo objectivo é a discussão da possibilidade e legitimidade de um uso inócuo do conceito de Reconquista na actualidade. Concretizando uma vincada oposição argumentativa, Francisco García Fitz (pp. 79-98) e Alejandro García Sanjuán (pp. 99-119) expõem dois raciocínios que poderiam sintetizar as duas correntes que desde o criticismo do final dos anos 1970 vigoram no debate historiográfico, acrescentando-lhes, contudo, 
considerações que as actualizam. Poder-se-á caracterizar a posição de García Fitz como pragmatista, uma vez que este historiador coloca como argumento a consagração já atingida pelo conceito não só em contexto peninsular, mas também em contexto internacional, consagração essa que lhe empresta um carácter prático, por um lado, e útil, por outro, no sentido em que define inequivocamente um campo de estudos cujas balizas cronológicas e geográficas se apresentam bem definidas, assim como o seu campo temático, conceptual e teórico. A esta posição opõe-se a crítica de García Sanjuán, evidenciada à partida pelo título empregue, que define o termo Reconquista como uma bomba historiográfica a desarmadilhar. A posição assumida neste texto convida a reflectir que o emprego continuado deste conceito equivale ao perpetuar de um programa ideológico que tem nas suas bases os argumentos sustentadores da unidade e do imperialismo espanhóis, hoje transformados pela acção do franquismo e do nacional-catolicismo e que alimentam não só uma parte da historiografia académica, mas também da História produzida fora do meio universitário, assim como, por outro lado, a comunicação e propaganda da extrema-direita espanhola.

7 Não se pense, mesmo assim, que o argumento pragmático do Professor García Fitz radica apenas na comodidade do conceito. No seu artigo, García Fitz faz uma recuperação dos argumentos que sustentam que, embora extemporâneo, o conceito de Reconquista possa ser perfeitamente aplicável para a descrição das mentalidades que presidiram ao fenómeno da expansão Cristã em detrimento dos poderes islâmicos do sul da Península. Ainda sobre o pragmatismo desta posição, reconheça-se que a tentativa de fintar a palavra exigirá um esforço conceptual considerável para gerar um termo que de forma tão ampla abarque as realidades compreendidas por este complexo historiográfico e o defina, simultaneamente, conferindo-lhe especificidade dentro do panorama dos estudos medievais à escala internacional.

8 Não obstante, é necessário reter que este conceito apresenta um conjunto de fragilidades, a começar pela sua base ideológica vincada que, no plano da constituição do campo de estudos, subordina necessariamente as realidades islâmicas ao triunfalismo cristão. Assiste-se, na melhor das hipóteses, a uma condenação da civilização andaluza a um simples papel de cenário colorido dos feitos dos cavaleiros do norte, ou, na pior, ignorando completamente o campo muçulmano e os seus contributos para a explicação do devir histórico, constituindo o mouro como o adversário que foi necessário expulsar para a concretização final dos impérios ibéricos profeticamente anunciados. É uma subordinação teórica que tem também como efeito a subalternização do trabalho dos arqueólogos dedicados aos contextos islâmicos, arabistas, e restantes medievalistas que se dedicam ao estudo da civilização do alAndalus. Contributo que, no fundo, aponta para uma cisão excessivamente artificial tanto da análise como da síntese, ao invés de as promover no sentido da confluência dos dados para um maior escopo de compreensão do que foi a Península Ibérica nos séculos de convívio, mais ou menos pacífico, entre Cristãos e Muçulmanos.

9 E se uma das fragilidades do emprego do termo assenta nesta distorção dos resultados da análise, outra resulta da persistência de concepções erróneas, relativas não só à ideia de uma relação directa entre a monarquia de Toledo e os reis asturianos, mas também à noção de uma continuidade entre o que se pretende plasmar como mentalidade da reconquista na ideologia dos homens dos séculos XI-XV e o mundo contemporâneo. Conforme G. Sanjuán coloca: "resulta necessário poner de manifiesto que entre el proyecto medieval de destrucción de al-Andalus y la moderna noción de Reconquista 
existe una discontinuidad absoluta que impide considerarla como una noción auténtica" (p. 101). Ora, a questão ganha mais fôlego quando, segundo o texto do autor, se testemunha uma tentativa de reanimação do conceito de Reconquista no presente, à revelia dos debates académicos em torno do mesmo. Aliás, conforme G. Sanjuán nos conduz na sua exposição, talvez não seja de ignorar a relação que a emergência dos populismos e da extrema-direita no hemisfério ocidental tem com a reactivação deste e de outros conceitos. No final dos anos 1990 do século passado era possível, para os autores de Portugal. 0 sabor da Terra considerar os ideais do Estado Novo algo de ultrapassado ${ }^{10}$, aos quais o progresso do país e do Ocidente se encarregaria de colocar a devida lápide funerária. Volvidos pouco mais de duas décadas assiste-se, na Europa e na América, com as devidas modelações culturais e territoriais, à ressurgência de valores autoritários, despóticos e discriminadores dos seres humanos e das suas opções. Os usos da medievalidade têm tido um papel neste fenómeno. G. Sanjuán ilustra-o bem relativamente ao caso espanhol e à sua relação com o conceito de Reconquista. À escala global, recorde-se o exemplo da alt-right de orígem Norte-americana, e das campanhas em torno de Trump ${ }^{11}$, que por meio da cultura meme canalizada nas redes sociais, tem vindo a munir-se de uma imagética grosseiramente apropriada a partir de representações da medievalidade, sobretudo da Cruzada e das Ordens Militares. Imagens tornadas expressões glorificadas de uma cultura de intolerância e de um apelo ao choque violento contra as expressões humanas, sejam elas de credo, raça ou opção de género e/ou sexual, que não caibam dentro do modelo de sociedade conservadora que estes movimentos políticos pretendem defender.

10 Na sua expressão provinciana, a extrema-direita portuguesa não tem resistido ao apelo de canalizar as mesmas estratégias discursivas, embora a sua falta de substracto intelectual não a tenha permitido fazer mais que uma simples cópia e colagem dos modelos postos já em prática pelos movimentos análogos nas esferas atlântica anglosaxónica e continental europeia, necessariamente adaptando as efígies celebradas ao contexto histórico português ${ }^{12}$. Contudo, se o ressurgimento deste espectro político em Portugal tem aproveitado o imaginário da Reconquista, não é este universo que deu expressão, maioritariamente, às apropriações da história levadas a cabo pelo programa cultural do Estado Novo e pelos movimentos intelectuais nacionalistas que o antecederam.

11 É com esta questão que se inicia a segunda parte da obra, dedicada a perspectivas territoriais sobre o tema. $O$ artigo de Luís Filipe Oliveira (pp. 123-140) centra a questão em Portugal, permitindo compreender o devido peso que a ideia de Reconquista teve para os sectores nacionalistas, católicos e conservadores portugueses entre os séculos XIX e XX. Assumindo um lugar menor relativamente às narrativas dos feitos ultramarinos, as realizações da construção do território continental português, figuradas quer em Reconquista, quer em Cruzada, não deixaram de figurar no aparato cultural e ideológico destes sectores. Todavia, o edifício ideológico e historiográfico arquitectado segundo o modelo de apogeu e declínio que explicava a nação, punha a tónica nas glórias de além-mar, reduzindo a Reconquista e os seus heróis, de acordo com a expressão de L. Oliveira, a "um prólogo indispensável" (p. 127). O autor sublinha que, nas memórias do reino, este distanciamento face à centralidade da ideia de Reconquista enquanto elemento explicativo tinha precedentes: para a historiografia medieval do reino, o distanciamento face à ideologia neogótica e de Reconquista constituía uma estratégia discursiva que procurava nivelar o estatuto das realezas cristãs da Hispânia, e assim reforçar a autonomia do reino conquistada face à hegemonia da coroa Leonesa. 
Por outro lado, se as crónicas medievais do reino prestavam menos atenção à continuidade entre a monarquia de Toledo e a monarquia das Astúrias, por sua vez abriam mais espaço a outros discursos legitimadores da construção dos poderes e do território, extrâneos ao pensamento peninsular, como o sendo o da ideologia de Cruzada.

O artigo de Luísa Trindade (pp. 141-161), focando-se em aspectos materiais da transição de poder entre Muçulmanos e Cristãos, aporta a perspectiva das mutações urbanísticas ocorridas com a rendição das urbes islâmicas aos poderes nortenhos. Através da sua exposição, reconhece-se que as diferentes leituras na lógica urbana dos dois paradigmas vão provocar, a ritmos diferentes, alterações no espaço urbano que vão da alteração do sistema viário à transformação da casa-pátio mediterrânica, atendendo às lógicas sócio-económicas e religiosas dos novos dominadores dos espaços. De acordo com a autora, não terá sido um fenómeno homogéneo: os ritmos de ocupação, o maior ou menor interesse dos conquistadores e as garantias conferidas aos autóctones, bem como as estratégias de convívio construídas com os vencidos em muito determinaram a transição entre modelos. Para a discussão que dirige o volume, talvez se possa considerar que a ideia de Reconquista tenha que ser, mais uma vez, revista em face destes dados, uma vez que a acção dos poderes cristãos vem romper com as lógicas urbanísticas do Sul, que sendo tipicamente islâmicas, se estendem no tempo da cidade tardo-antiga "que o período de mais de dois séculos de domínio visigodo não parece ter alterado nos fundamentos" (p. 155).

Dentro das perspectivas territoriais, os artigos de Stefano M. Cingolani (pp. 164-186) e Martín Alvira (pp. 187-229) lançam olhares sobre o tema da ideologia Cristã da guerra no contexto dos condados catalães e da Coroa de Aragão. S. Cingolani traça um panorama balizado entre os séculos IX e XII nos territórios da Marca de Espanha que se pode sintetizar na ausência de uma verificação de um discurso sobre a guerra que partilhe a matriz neogótica ou reconquistadora dos discursos leoneses nestes territórios, havendo uma lenta penetração dos discursos sobre a guerra santa Cristã e a Cruzada a partir do século XI, tendo como factores maiores desta difusão a influência papal, as Ordens de Cluny e do Templo, e, finalmente, as estratégias mediterrânicas dos condes de Barcelona. O autor não deixa, ainda assim, de terminar o artigo colocando reservas quanto à verdadeira extensão da penetração destas lógicas discursivas na mentalidade dos guerreiros do norte levantino. Já Martín Alvira apresenta uma profunda análise das narrativas e da documentação da Coroa aragonesa, entre os reinados de Afonso, o Trovador e de Jaime I, o Conquistador. Apresentando um sentido de sequência relativamente ao artigo anterior, M. Alvira traça o panorama do desenvolvimento da ideologia de guerra santa nas fontes da monarquia aragonesa, podendo detectar-se a construção de um discurso que evita a legitimação da guerra a partir das formulações neogoticistas, mas que reclama as ideias de recuperação e restauração de um território anteriormente cristão, que se vai procurar articular, nem sempre de forma coerente, com a difusão das ideias cruzadísticas.

14 A terceira parte deste livro foi consignada à reunião das perspectivas islâmicas sobre a ideologia da guerra. Procurando resgatar o devir ideológico do campo muçulmano, as três contribuições que o compõem demonstram que não foi só o campo cristão a sofrer mutações na forma de legitimar a guerra e a violência. Javier Albarrán (pp. 233-257) lança um olhar sobre fontes cronísticas que se prolonga entre a fitna e o século XII, que ilustra o paralelo andaluz dos discursos de reconquista e de recuperação do território. 
Embora com matizes resultantes quer do material heurístico, quer da natureza cultural e religiosa do mundo islâmico, J. Albarrán conclui que a partir dos centros de poder andaluz e marroquino registaram-se discursos cuja intencionalidade foi representar o território peninsular como projecto de uma Jihad de sentido recuperador e renovador. Abigail Balbale (pp. 259- 279), no seu estudo sobre o tratamento historiográfico da figura de Ibn Mardanī̌s, centrado sobretudo numa fonte do século XVII, demonstra que, mesmo para lá da conquista de Granada em 1492, os historiadores muçulmanos foram recuperando as memórias do al-Andalus, transformando-as e dando novos moldes aos seus protagonistas, procurando a atribuição de sentidos ao destino sofrido pelos domínios muçulmanos da Hispânia. Finalmente, Bárbara Boloix Gallardo (pp. 281-302) traça um percurso através dos discursos produzidos em contexto Nazári, que, através de um jogo linguístico tiveram a virtude de associar ao nome da dinastia uma imagem triunfalista com efeitos propagandísticos e edificantes, permitindo a manutenção de uma representação vitoriosa dos emires de Granada, apesar dos contextos militares desfavoráveis que a família foi sabendo navegar até ao ocaso do seu reino.

Com o texto de Maria Alegria Fernandes Marques (pp. 305-324) inaugura-se a quarta parte da obra, dedicada a abordagens metodológicas e reflexões gerais. A autora procura fornecer a perspectiva papal relativa às ideias de Reconquista e Cruzada na Península Ibérica, traçando o percurso da promoção da luta contra o Islão peninsular encetada pelo papado. Apresentando, em primeiro lugar, as questões da progressiva transformação da guerra contra o Islão numa guerra santa a partir do século XI, a autora passa a desenvolver as consequências, em solo hispânico, da formulação da ideia de Cruzada a partir do Concílio de Clermont, em 1095. A narrativa da autora apresenta os caminhos da penetração desta ideologia na Península e os seus protagonistas, recuperando a ideia de que a Cruzada Peninsular, na óptica da cúria papal, teria sido um fôlego de pouco mais de um século, desenvolvido ao longo de Undecentos e abandonada logo após o sucesso das Navas. A autora afirma que em 1213 "morria a cruzada de Espanha para a Santa Sé" (p. 315), apesar de, noutras passagens, referir ainda a permanência de indulgências e benefícios posteriormente cedidos pelo trono de S. Pedro para a prossecução do combate ao Islão. Na sua narrativa, o Salado parece já uma empresa extemporânea, realização de uma época em que a promoção da ideia de Cruzada estava já ultrapassada, tendo sido quase que mecanicamente substituída pela ideia de missionação, conforme a autora propõe no seu último parágrafo. Um ponto de vista que coloca problemas ao conjunto de dados arrolados relativos à Cruzada Peninsular entre os séculos XIII e XV, que sob esta perspectiva ficam numa situação de difícil interpretação.

16 Fermín Miranda García (pp. 325-341) detém-se no conceito de dilatatio christianitatis para contribuir com a sua formulação tardo-antiga e carolíngia, bebida dos textos vetero-testamentários e vertido, finalmente, no aparato diplomático e cronístico do Império e das monarquias cristãs da Península. Numa vertente de análise historiográfica, Martín F. Rios Saloma (pp. 343-363) elabora uma discussão de aspectos da obra de Sánchez Albornoz que procura compreender as formulações do historiador espanhol à luz do seu percurso e da influência das diferentes conjunturas e paragens em que foi elaborando a sua obra.

17 A quinta secção, composta por apenas dois artigos, inicia-se com o contributo de David Porrinas González (pp. 367-400) que procura desconstruir a associação entre Rodrigo Díaz, o Cid, e a Reconquista, par consagrado pela historiografia, tentando compreender 
os limites do discurso legitimador da guerra presente na acção do Campeador e integrálo nas lógicas de construção de um domínio a partir de Valência. Munindo-se de um leque diversificado de fontes, Porrinas González percorre várias representações de Rodrigo Díaz, procurando reintegrá-lo na mentalidade do seu tempo e compreender a modelação das narrativas consoante a maior ou menor proximidade ao projecto político deste protagonista. 0 outro artigo deste capítulo, pela mão de Carlos Barquero Goñi (pp. 401-417) trata de outros actores não-régios do confronto entre Cristandade e Islão peninsulares - os freires das Ordens Militares - listando referências à ideia de Reconquista nas suas fontes narrativas e detendo-se de forma mais dilatada para os casos de Calatrava e de Santiago.

Por último, a sexta parte do volume dedica-se à discussão do tema nas suas bases materiais e projecções visuais. J. Santiago Palacios Ontalva (pp. 421-460) procura lançar, a partir do plano da Arqueologia, o debate em torno do emprego do termo Reconquista e avaliar a sua validade teórica e metodológica no quadro do estudo da cultura material. Este trabalho não só apresenta o mérito de contrariar a hegemonia que a História enquanto compartimento disciplinar tem exercido sobre a discussão do conceito, como também olha para os diferentes campos conceptuais que os arqueólogos têm constituído em torno das realidades de confronto e de transição entre os dois universos religiosos peninsulares. Concentrando-se nas realidades materiais almóadas, Isabel Cristina Ferreira Fernandes (pp. 461-482) retrata a cultura material do sul de Portugal a partir dos levantamentos que, nas últimas décadas, têm frutificado num aprofundamento do conhecimento do período Califal de finais do século XII e primeira metade da centúria seguinte. A autora demonstra o reflexo do projecto de unificação $\mathrm{e}$ reforma religiosa em níveis bastante distintos, que alcançam a arquitectura mas também os objectos do quotidiano, o que permite ultrapassar a leitura dos textos e compreender a amplitude da relação entre ideologia e quotidiano, muitas vezes difícil de atingir nas esferas das evidências puramente textuais. Encerrando o volume, Francisco J. Moreno Martín (pp.484-518) reconstitui-nos os quadros visuais da propaganda franquista, construída em torno de uma apropriação da ideia de Cruzada, vertida depois para uma construção contemporânea da missão do caudillo.

Reconquista: um conceito escatológico e hierarquizador. Pragmaticamente consagrado pela historiografia e decididamente persistente. Perante os trabalhos reunidos neste volume apura-se uma cronologia vincadamente fértil nas manifestações da ideologia da guerra tecidas de parte a parte, entre Cristãos e Muçulmanos. $O$ termo não escapa à crítica de formular a explicação do devir histórico da Península Ibérica na base de uma narrativa arquetipal de queda e redenção protagonizada pelos poderes Cristãos do norte. Que, ao nível dos poderes, o mundo Cristão se foi impondo paulatinamente ao mundo Muçulmano, é certo. Que a cultura intelectual dos homens do norte foi justificando esse processo com um discurso progressivamente mais universal e totalizante, antevendo as representações do Império, resulta também evidente - os estudos reunidos neste livro testemunham-no. Contudo os cavaleiros do Norte não foram sempre os triunfais vencedores, e as latitudes meridionais não foram o mero palco do destino anunciado dos guerreiros Cristãos. Eram espaço disputado, povoado e produtor de riqueza material e cultural, organizado por uma rede de poderes islâmicos que se estruturavam da urbe à kūra, projectando-se à taifa ou, mesmo, ao califado, em Córdova ou do outro lado do Estreito. Não se olvide que a aceitação acrítica do conceito de Reconquista é, simultaneamente, enviesar a observação das realidades do sul Muçulmano, tomando-as como anomalia histórica enxertada no espaço Ibérico a partir 
do ano de 711, bem como fazer a sua leitura histórica de forma teleológica, com os olhos postos no ano de 1492 .

Pelo contrário, nos alicerces desta oposição jazem as populações que humanizavam os territórios progressivamente dominados pelos reinos do norte, com o seu credo, a sua língua e cultura, as suas realidades materiais, que correspondiam muitas vezes a estruturas remotas, componentes desse grande complexo histórico-geográfico que é a bacia do Mediterrâneo. Eram todos mouros? Quando os Cristãos vieram deixaram de o ser imediatamente? Que herança deles persiste? Retome-se a reflexão recente de Cláudio Torres: "D. Afonso Henriques não conquistou Lisboa aos mouros, foi aos cristãos"13. Que sirva para se compreender a necessidade de aprofundarmos o conhecimento sobre a Idade Média Peninsular, mormente no que toca às suas realidades materiais e à grande permanência que é a componente humana da Reconquista. Nesse sentido, os investigadores do campo muçulmano têm fornecido pistas e conjuntos de dados que nos orientam o olhar para as comunidades que transitaram entre o domínio Cristão e o domínio Muçulmano. É de assinalar que a grande maioria dos contributos para este volume dedicados ao campo Cristão incidam, maioritariamente, sobre textualidades. Porém, se o objectivo for a crítica e compreensão do termo Reconquista, a integração das realidades do sul da Península na esfera de poderes nortenhos carece de uma maior compreensão do que aconteceu depois da tomada destes espaços, conferindo à ideia que se tem deste processo de transformação as devidas matizes, seus limites e características locais - só possíveis de atingir complementando os dados presentes nas memórias textuais deste processo com os dados arrolados pelo estudo da cultura material, dos espaços e da componente humana ${ }^{14}$.

21 Rematando, saúda-se a publicação do resultado dos trabalhos ocorridos em Palmela em 2018. Pela diversidade de aspectos, pontos de vista e ângulos de aproximação, o volume resulta num valioso contributo para o enriquecimento do debate em torno do conceito de Reconquista. Como acima se disse, o termo continua a inspirar divisões no seu emprego e na sua abordagem, evitando tornar-se um artefacto teórico datado. Talvez assim permaneça, já que a sua natureza original radica numa expressão de oposição e conflito.

\section{NOTAS}

1. Os sucessivos projectos de investigação $I+D$ «Génesis y desarrollo de la guerra santa cristiana en la Edad Media de Occidente peninsular (siglos X-XIV)» [HAR2012-32790] e «Confrontatio. Violencia religiosa en la Edad Media peninsular: guerra, discurso apologético e relato historiográfico (ss. X-XV)» [HAR2016-74968-P] ambos financiados pela Secretaría de Estado de Investigacion, Desarrollo e Innovación do Ministerio de Economía, Industria y Competitividad Espanhol, tendo agregado à Universidad Autónoma de Madrid instituições como a École Pratique de Hautes Études de Paris, o Gabinete de Estudos sobre a Ordem de Santiago de Palmela e a Casa de Velazquéz de Madrid, entre outras, que levaram a cabo iniciativas académicas que têm congregado investigadores de múltiplas nacionalidades afectos a estas e a outras instituições; 
2. Refiram-se, para além do volume em apreciação, os seguintes: AYALA MARTÍNEZ, Carlos de; FERNANDES, Isabel Cristina Ferreira (coords.) - Cristãos contra Muçulmanos na Idade Média Peninsular. Bases ideológicas e doutrinais de um confronto (séculos X-XIV) / Cristianos contra Musulmanes en la Edad Media Peninsular. Bases ideológicas y doctrinales de una confrontación (siglos X-XIV). Lisboa: Colibri/Universidad Autónoma de Madrid, 2015; AYALA MARTÍNEZ, Carlos de; HENRIET, Patrick; PALACIOS ONTALVA, J. Santiago (eds.) - Orígenes y desarrollo de la Guerra Santa en la Península Ibérica. Palabras y Imágenes para una legitimación (siglos X-XIV). Madrid: Casa de Velázquez, 2016; AYALA MARTíNEZ, Carlos de; PALACIOS ONTALVA, J. Santiago; Ríos SALOMA, Martín (eds.) Guerra Santa y Cruzada en el Estrecho. El Occidente Peninsular en la primera mitad del siglo XIV. Madrid: Silex, 2016; AYALA MARTíNEZ, Carlos de; PALACIOS ONTALVA, J. Santiago (eds.) - Hombres de religión y guerra. Cruzada y guerra santa en la Edad Media peninsular (siglos X-XV). Madrid: Silex, 2018. 3. Recorde-se, enquanto marco desta problematização, a obra de BARBERO, A; VIGIL, M. - Los orígenes del feudalismo en la Península Ibérica. Barcelona: Crítica, 1978.

4. MATTOSO, José - "Portugal no Reino Asturiano-Leonês". in MATTOSO, José (dir.) - História de Portugal. Vol. 1. Antes de Portugal. Coord. José Mattoso. Lisboa: Círculo de Leitores, 1992, pp. 441-444.

5. BEIRANTE, Maria Ângela - “A «Reconquista» Cristã". in SERRÃO, Joel; MARQUES, A. H. de Oliveira (dirs.) - Nova História de Portugal. Vol. II. Portugal das Invasões Germânicas à "Reconquista". Coord. A. H. de Oliveira Marques. Lisboa: Presença, 1993, pp. 253-255.

6. Veja-se o contributo recente de PICOITO, Pedro - "Reconquista e Guerra Santa na Historiografia Portuguesa do Último Meio Século. Exílio e Regresso". in FERNANDES, Isabel Cristina F. (coord) - Entre Deus e o Rei. O Mundo das Ordens Militares. Vol. I. Palmela: Câmara Municipal / GEsOS, 2018, pp. 189-208.

7. A este título refira-se o artigo de opinião assinado por Hermenegildo Fernandes no Público [Em linha] (2 de Outubro de 2020). [Consultado a 7 fevereiro 2021]. Disponível em https:// www.publico.pt/2020/10/02/opiniao/noticia/mesquita-1933512.

8. Exposição aberta ao público de 20 de Novembro de 2020 a 25 de Abril de 2021. Disponível em http://museudearteantiga.pt/exposicoes/guerreiros-e-martires [Consultado a 7 Fevereiro 2021].

9. Ou, nas palavras dos seus coordenadores: "Os dois lados em contenda estão aqui presentes, através da palavra e da escrita, de peças arqueológicas, de relicários, de livros e objectos mágicos. Identificação de um País foi o título-homenagem que quisemos encerrar «Guerreiros e Mártires». A construção de uma nova nação e os ecos, cada vez mais difusos, do passado fazem-se sentir através da afirmação de uma nova realidade, com raízes mais a norte, que não exclui as formas de expressão artística ligadas à tradição islâmica. As importações das oficinas levantinas, que se prolongam para lá de 1250, e a continuação do uso da língua árabe nas mourarias são a expressão derradeira de uma memória que só a arqueologia conseguiu, nos últimos 40 anos, resgatar de forma efectiva".: CAETANO, Joaquim Oliveira; MACIAS, Santiago (coords.) - Guerreiros \& Mártires. A Cristandade e o Islão na formação de Portugal. Catálogo da exposição. Lisboa: IN/MNAA, 2020, p. 11.

10. “Já não estamos obcecados pela necessidade propagandística de afirmar que «Portugal não é um país pequeno», ou para proclamarmos as suas glórias passadas, à falta de confiança nas presentes. Já não sabemos o que quer dizer «o altar sagrado da Pátria». O ideal «Deus, Pátria, Família» acarreta implicações tão suspeitas que ninguém se atreve já a proclamá-lo, por mais respeito e veneração que tenha por cada um dos seus componentes": MATTOSO, José; DAVEAU, Suzanne; BELO, Duarte - Portugal. O sabor da Terra. Um retrato histórico e geográfico por regiões. Lisboa: Temas e Debates / Círculo de Leitores, 2017, pp. 11-12 (1. ed. 1998).

11. Veja-se, a respeito da evolução dos usos da medievalidade na esfera pública e política do século XXI, ELLIOT, Andrew - Medievalism, Politics and Mass Media. Appropriating the Middle Ages in the Twenty-First Century. Woodbridge: Boydell \& Brewer, 2017.

12. "Como Ventura usou o imaginário nacionalista do Estado Novo e imitou Donald Trump”. Expresso [Em linha] (22 de Janeiro de 2021). [Consultado a 7 Fevereiro 2021]. 
Disponível em https://expresso.pt/presidenciais2021/2021-01-22-Como-Ventura-usouo-imaginario-nacionalista-do-Estado-Novo-e-imitou-Donald-Trump? fbclid=IwAR3HDFqZnbvaV6naot-LXUn8rZk4EPcOeRYD7AQU4XQRxNcLjZNwY5Wx6J8 E MARTINS, Pedro; MIGUÉLEZ, Alicia - "Opinião: Os usos da Idade Média no discurso político atual". Público [Em linha] (2 de Fevereiro de 2021). [Consultado a 7 Fevereiro 2021]. Disponível em https://www.publico.pt/2021/02/04/opiniao/opiniao/usos-idademedia-discurso-politico-atual-1948960.

13. TORRES, Cláudio - "D. Afonso Henriques não conquistou Lisboa aos mouros, foi aos cristãos". Sábado [Em linha] (23 de Fevereiro de 2018). [Consultado a 7 de Fevereiro]. Disponível em https://www.sabado.pt/vida/detalhe/claudio-torres-d-afonsohenriques-nao-conquistou-lisboa-aos-mouros-foi-aos-cristaos.

14. Evoque-se, no âmbito das potencialidades deste tipo de abordagem, sobretudo a utilização de um conhecimento aprofundado do espaço em questão como chave para a interpretação dos dados do texto, MAGALHÃES, Joaquim Romero de - "Uma interpretação da Crónica da Conquista do Algarve". in Actas das II Jornadas Luso-espanholas de História Medieval. Vol. I. Porto: INIC, 1987, pp. 123-133.

\section{AUTORES}

\section{CLAUDIO NETO}

Cardiff University, Cardiff School of History, Archaeology and Religion, CF 10 3EU Cardiff, Reino Unido. Universidade Nova de Lisboa, Faculdade de Ciências Sociais e Humanas, Instituto de Estudos Medievais, 1070-312 Lisboa, Portugal. claudioacnneto@gmail.com 